\title{
Does Education Level Differentiate Adults’ Attitudes Towards Physical Activity during COVID-19 Pandemic? A Preliminary Study
}

\author{
Evangelos Bebetsos ${ }^{1 *}$, Christos Konstantinidis ${ }^{1}$
}

${ }^{1}$ Democritus University of Thrace, Komotini, GREECE

*Corresponding Author: empempet@phyed.duth.gr

Citation: Bebetsos, E., \& Konstantinidis, C. (2021). Does Education Level Differentiate Adults' Attitudes Towards Physical Activity during COVID-19 Pandemic? A Preliminary Study. Aquademia, 5(2), ep21009. https://doi.org/10.21601/aquademia/10965

\begin{tabular}{|c|c|}
\hline ARTICLE INFO & ABSTRACT \\
\hline Received: 1 Feb. 2021 & spread of the COVID-19 pandemic raises concerns about \\
\hline Accepted: 17 Mar. 2021 & $\begin{array}{l}\text { increased panic and increased anxiety in people who are trapped in either a real or a theoretical Coronavirus } \\
\text { threat. The aim of this preliminary study was to investigate the contribution of education level in predicting } \\
\text { Physical Activity's attitudes and intention of adults during a Pandemic. The sample consisted of } 904 \text { people, } 417 \\
\text { men and } 487 \text { women, aged } 18-70 \text { years. The participants completed the Greek version of the "Theory of Planned } \\
\text { Behavior" questionnaire. Analyzes indicated that higher education level increases people's attitudes towards PA } \\
\text { and during COVID-19. Overall, education level is a valued factor and it seems to accompany relatively stronger } \\
\text { intentions even during life threatening conditions. }\end{array}$ \\
\hline
\end{tabular}

Keywords: planned behavior theory, education level, pandemic

\section{INTRODUCTION}

Coronavirus disease, known as COVID-19, is a global, which has affected the daily routine of all people (WHO, 2020). Education is a field it could not be ineffective from this pandemic (Ajzen \& Fishbein, 1980). Rapid spread and increased morbidity and mortality, due to COVID-19, colleges and universities were closed to prevent further spread of the virus. This action caused a chain reaction in the academic field. First of all, the physical removal from the colleges and universities creates social distancing and more staying at home. This abrupt change of daily habits affected mental health, academic performance, individual and family economy, academic progression, family life, and social networks (Cao et al., 2020; Mudenda et al., 2020).

Students' reported that COVID-19 pandemic has made them suffer from mental health disorders (Cao et al., 2020). School closures, loss of routine and restricted social connections are mainly causes for the worsening of preexisting mental health conditions (Liang et al., 2020; Zhai \& $\mathrm{Du}, 2020)$. These impacts may affect the academic performance of the students because mental health is highly associated with a student's academic performance (Lee, 2020). To mitigate this problem, online learning was introduced as an attempt to restore the previous academic life. Unfortunately, face-to-face interaction, laboratory tests and practical work they cannot be left unaffected in a negative way (Sahu, 2020).
COVID-19 affects also the social and family life. As it was mentioned, impact of this affection isn't the same for all people. Although the majority of young people reported receiving increased social support from family and friends (Zhang \& Ma, 2020), there is a minority of them who felt that they received less social support from family and friends, which in turn can affect their academic life (Oi et al., 2020).

There are many decisive factors that may play an important role in predicting certain behaviors, such as exercising/physical activity. Research suggests that one theory that can provide answers to such problematic behaviors is the Theory of "Planned Behavior" (Ajzen, 2012).

Also, a behavior can be completely under the control of the individual, that is, the individual has the ability to decide whether to demonstrate it or not. But regardless of a person's intention to exhibit a behavior, there are usually obstacles that are likely to create problems. These barriers are internal factors such as skills, knowledge, planning, and external factors such as time, opportunities, collaboration with others, etc. (Ajzen, 2012). Similarly, Armitage and Conner (2001) reported that this theory is an established model that represents $39 \%$ of intentional variation and $27 \%$ of behavioral variation.

Research (Theodorakis, 1994; Theodorakis et al., 1991) examined some additional factors related to behavioral prediction. Research on information and knowledge supports the hypothesis that the consistency between attitudes and behavior will increase as a function of the amount of 
knowledge and information available (Bebetsos \& Konstantinidis, 2021; Wilson, Kraft, \& Dunn, 1989). Research showed that knowledge about attitude might moderate the effects. The reasons were that knowledgeable people may be more likely to know why they do something, and less knowledgeable people may have inconsistent beliefs about the attitude. Finally, people without knowledge may have weaker attitudes, which may change more easily (Fazio, 1986).

Additionally, information has often been mentioned as an important factor in understanding attitudes' consistency with behavior (Ajzen \& Madden, 1986; Theodorakis, 1994). Limited information and knowledge about the behavior can represent a serious obstacle, preventing individuals from carrying out the behavior in question (Theodorakis, 1994). Information is a construct that has not drawn much attention in recent research based on Planned Behavior Theory.

In the present research, the specific theory was used to investigate if education level differentiates individual's engagement with physical activity, during COVID-19 first lockdown. This effort highlights the uniqueness in both Greek and international studies, due to research-gap.

\section{METHODS}

\section{Subjects and Instrument}

The sample consisted of 904 Native Greek individuals, 417 men (46.2\%), and 487 women (53.8\%), between the ages of 18 and 70 years $(M O=36.26, S D=12.48)$. All subjects completed the Greek version (Theodorakis, 1994) of a questionnaire based on the "Theory of Planned Behavior" (Ajzen \& Madden, 1986).

More specifically:

Attitudes were estimated by the mean score of responses to the question "For me to exercise regularly for the next 2 months, is...”. Responses were rated on 7-point scale, on five bipolar adjectives ( $7=$ good $-1=$ bad, $1=$ foolish $-7=$ smart, $7=$ healthy $-1=$ unhealthy, $7=$ useful $-1=$ unuseful, $7=$ pleasant $1=$ unpleasant).

Subjective Norms were estimated by the mean score of responses to four questions "If I exercise regularly for the next 2 months, individuals who are important to me...”; "Generally, I enjoy doing what some important individuals want me to do"; "Some individuals who are important in my life, believe that I must exercise regularly for the next 2 months"; "Generally, I like doing what some important individuals want me to do". Responses were rated on 7-point scales. For questions 1, 2 and 4 responses were rated on $1=$ will strongly disagree, to $7=$ will strongly agree and for question 3 responses were $1=$ very impossible, to $7=$ very possible.

Role Identity was measured by four questions: "I consider myself to be able to exercise regularly for the next 2 months"; "I consider myself a person that will exercise regularly for the next 2 months"; "It's in my character (temperament) to exercise regularly for the next 2 months"; "Generally, I am the type who is going to exercise regularly for the next 2 months". Responses were rated on 7-point scales from 1=strongly disagree to $7=$ strongly agree. This scale was adapted from Theodorakis (1994).
Attitude Strength was measured using eight questions (Theodorakis, 1994). The items were: "How certain are you that you are going exercise regularly for the next 2 months?”; "Is it right for you to exercise regularly for the next 2 months?”; "I feel very sure that I will exercise regularly for the next 2 months"; "Is it important for you personally, to exercise regularly for the next 2 months?"; "How interested are you in exercising regularly for the next 2 months?"; "For me to exercise regularly for the next 2 months is..."; "With the knowledge I have, I think I will exercise regularly for the next 2 months"; "Do you find it interesting to exercise regularly for the next 2 months?". Responses were rated on 7-point scales, for the first item from $1=$ very uncertain to $7=$ very certain, for the second and sixth items from $1=$ not at all to $7=$ =very much so, for the third and seventh items from $1=$ strongly disagree to $7=$ strongly agree, for the fourth item from $1=$ not important at all to $7=$ very important and for the fifth and eighth items from $1=$ not at all to $7=$ very much.

Knowledge about the specific subject was measured by the mean score of responses to four questions: "Some of us are very well informed about exercising regularly, while other individuals aren't. How well informed about exercising regularly for the next 2 months do you believe that you are?"; "If someone told you to write anything you know about exercising regularly, how much could you write?"; "In comparison to other people, I believe that I am very well informed on the issue of about exercising regularly for the next 2 months", "How much do you think that you know on the issue of about exercising regularly for the next 2 months?". The answers were rated on 7-point scales. For the first question from $1=$ not informed at all to $7=$ =very well informed, for the second question from $1=$ very little to $7=\mathrm{a}$ lot, for the third from $1=\mathrm{I}$ strongly disagree to $7=\mathrm{I}$ strongly agree and for the last question from $1=$ no knowledge at all to $7=\mathrm{a}$ lot of knowledge. This scale was adapted from Theodorakis (1994).

Information was measured by four questions: "Some individuals told me that they pay attention to different information about exercising regularly. How much attention do you pay to different information about exercising regularly for the next 2 months?"; "How often do you pay attention to different material with information about exercising regularly?"; "I am very interested in any information regarding about exercising regularly for the next 2 months"; "How often do you pay attention to information regarding about exercising regularly?”. Responses were given on 7-point scales, for the first and fourth questions from $1=\mathrm{I}$ never pay attention to $7=\mathrm{I}$ very often pay attention, for the second from $1=$ never to $7=$ very often, for the third from $1=\mathrm{I}$ strongly disagree to $7=\mathrm{I}$ strongly agree and for the fourth from $1=\mathrm{I}$ never pay attention to $7=\mathrm{I}$ pay a lot of attention. This scale was adapted from Theodorakis (1994).

In the end, sample indicated its highest education level [135 Secondary Education level (15\%), 461 Undergraduate (51\%), 208 M.Sc. (23\%), \& 100 Ph.D. (11\%)].

\section{Procedure}

Research data was collected using an electronic form / questionnaire (Google Form), as the researchers considered its use mandatory in compliance with the new Coronavirus protection rules (COVID-19), avoiding unnecessary physical 
Table 1. Internal Consistency of the variables

\begin{tabular}{cc}
\hline Variables & Cronbach's alpha \\
\hline Attitudes & .89 \\
\hline Self-Identity & .87 \\
\hline Attitude Strength & .96 \\
\hline Subjective Norms & .85 \\
\hline Knowledge & .88 \\
\hline Information & .89 \\
\hline
\end{tabular}

Table 2. Univariate analyzes

\begin{tabular}{|c|c|c|c|c|c|c|c|c|}
\hline \multirow[t]{2}{*}{ Variables } & \multicolumn{2}{|c|}{ Secondary Education } & \multicolumn{2}{|c|}{ Undergraduate } & \multicolumn{2}{|c|}{ M.Sc. } & \multicolumn{2}{|c|}{ Ph.D. } \\
\hline & $M$ & $S D$ & $M$ & $S D$ & $M$ & $S D$ & $M$ & $S D$ \\
\hline Attitudes & 6.31 & 1.02 & 6.56 & .723 & 6.28 & .966 & $6.50^{\prime \prime}$ & .742 \\
\hline Knowledge & 4.25 & 1.30 & 4.27 & 1.46 & 5.02 & .119 & $5.53^{*}$ & 1.34 \\
\hline Information & 4.48 & 1.26 & 4.90 & 1.53 & 4.96 & 1.25 & $5.34^{*}$ & 1.30 \\
\hline
\end{tabular}

"p<0.05

contact. Data collection period lasted two months (April-May 2020, first lockdown). The reason for selecting the specific period is related to the duration of the outbreak of COVID-19 and its mandatory inclusion, in Greece.

Participants were informed about all the parameters and ethical issues that governed the research, such as voluntary participation, anonymity of participants, the right to leave voluntarily at any stage of the questionnaire and the exclusive use of the data for research purposes. They were informed by providing all the necessary information on the first page of the questionnaire. If they agreed they continued with the procedure.

\section{RESULTS}

The internal consistency (Cronbach, 1951), for the variables of all questionnaires ranged from .85 to .96 (Table 1).

Univariate analyses were conducted in order to find any differences among individual's education level. The analyses revealed the following statistically significant differences: (a) For the variable of "Attitudes": $\left[F_{(3,366)}=3.896, \mathrm{p}<0.05\right]$. More specifically, the post hoc multiple comparisons Scheffe test indicated the differences between Ph.D. individuals with the rest (Table 2). (b) For the variable of "Knowledge": $\left[F_{(3,366)}=\right.$ $3.75, \mathrm{p}<0.05]$. More specifically, the post hoc multiple comparisons Scheffe test indicated the differences between Ph.D. individuals with the rest (Table 2). And finally (c) for the variable of "Information": $\left[F_{(3,366)}=4.304, \mathrm{p}<0.05\right]$. More specifically, the post hoc multiple comparisons Scheffe test indicated the differences between Ph.D. individuals with the rest (Table 2).

\section{DISCUSSION}

According to modern data, the aging population and the concerns raised in relation to the prevalence of morbidity in the population and the rising cost of health care are at the highest rates in human history (Gruenberg, 1977; Shaw \& Spokane, 2008). These concerns bring to the surface the individual responsibility of each person for his personal behavior in relation to the protective roles of exercise in the health and well-being of individuals (Mokdad et al., 2004). There are many who believe that promoting healthy behavior and a healthy lifestyle offers the most promising means to offset the growing burden of disease that could result from the aging of our population (Fries, 2003).

In contrast to negative youth, physical activity has proven to be a behavior that has well-documented health benefits and is considered one of the most effective measures to prevent chronic diseases such as coronary heart disease and diabetes (Shaw \& Spokane, 2008). However, the relationship between education and physical activity is a sector that has not enlarged enough (Shaw \& Spokane, 2008). Especially in Greece, there is no research linking the level of education with physical activity during high-risk situations. This study takes into account some initial information into why physical activity may differ by education level.

Previous research has shown a positive relationship between leisure-time physical activity and education level (He \& Baker, 2005; Ransdell \& Wells, 1998). The current findings from our research agree with those previous results. According to Shaw and Spokane (2008), for low-education individuals, not working and job losses, such as during Pandemic, were associated with reduced physical activity, whereas for highly educated individuals the reverse was true.

In conclusion, high educated people perceive physical activity as a way out of the work routine and consider it as a part of positive management of their free time, in contrast to the people of low educational level, who, for the most part, include physical activity in their daily schedule. However, possible limitations of the present study should be mentioned, such as the psychological state of individuals in such difficult and unprecedented circumstances. Therefore, follow-up investigations could focus on taking into behaviors in the upcoming months, provided that society has returned to its previous, "normal", status.

Author contributions: All co-authors have involved in all stages of this study while preparing the final version. They all agree with the results and conclusions.

Funding: No external funding is received for this article.

Declaration of interest: The authors declare that they have no competing interests.

Ethics approval and consent to participate: Not applicable. 
Availability of data and materials: All data generated or analyzed during this study are available for sharing when appropriate request is directed to corresponding author.

\section{REFERENCES}

Ajzen, I. (2012) Handbook of theories of social psychology. Sage.

Ajzen, I., \& Fishbein, M. (1980) Understanding attitudes and predicting social behavior. Prentice-Hall.

Ajzen, I., \& Madden, T. J. (1986) Predictions of goal-directed behavior: Attitudes, intentions and perceived behavioral control. Journal of Experimental Social Psychology, 22, 453457. https://doi.org/10.1016/0022-1031(86)90045-4

Armitage, C. J., \& Conner, M. (2001) Efficacy of the Theory of Planned Behaviour: A meta-analytic review. British Journal of Social Psychology, 40, 471-499. https://doi.org/10.1348/ 014466601164939

Bebetsos, E., \& Konstantinidis, Ch. (2021). The contribution of the factors of "Knowledge" and "Information" to the intention for Physical Activity during COVID-19. Hellenic Journal of Nursing, 60(1), 74-80. (In Greek).

Cao, W., Fang, Z., Hou, G., Han, M., Xu, X., Dong, J., \& Zheng, J. (2020) The psychological impact of the COVID-19 epidemic on college students in China. Psychiatry Research, 287, 112934. https://doi.org/10.1016/j.psychres.2020. 112934

Cronbach, L. J. (1951) Coefficient alpha and the internal structure tests. Psychometrika, 16, 197-264. https://doi.org/10.1007/BF02310555

Fries, J. F. (2203) Measuring and monitoring success in compressing morbidity. Annals of Internal Medicine, 139, 455-459. https://doi.org/10.7326/0003-4819-1395_Part_2-200309021-00015

Gruenberg, E. (1977) The failure of success. Milbank Quarterly, 55, 3-24. https://doi.org/10.2307/3349592

He, X. Z., \& Baker, D. W. (2005) Differences in leisure-time, household, and work-related physical activity by race, ethnicity, and education. Journal of General Internal Medicine, 20, 259-266. https://doi.org/10.1111/j.15251497.2005.40198.x

Lee, J. (2020). Mental health effects of school closures during COVID-19. (2020) The Lancet Child \& Adolescent Health, 4, 421. https://doi.org/10.1016/S2352-4642(20)30109-7

Liang, L., Ren, H., Cao, R., Hu, Y., Qin, Z., \& Mei, S. (2020) The Effect of COVID-19 on Youth Mental Health. Psychiatry Quarterly, 91, 841-852. https://doi.org/10.1007/s11126020-09744-3

Mokdad, A. H., Marks, J. S., Stroup, D. F., \& Gerberding, J. L. (2004) Actual causes of death in the United States, 2000. JAMA, 291, 1238-1245. https://doi.org/10.1001/jama.291. 10.1238
Mudenda, S., Zulu, A., Phiri, M. N., Ngazimbi, M., Mufwambi, W., Kasanga, M., \& MiBanda, M. (2020) Impact of coronavirus disease 2019 (COVID-19) on college and university students: A global health and education problem. Aquademia, 4(2), ep20026. https://doi.org/ 10.29333/aquademia/8494

Qi, M., Li, P., Moyle, W., Weeks, B., \& Jones, C. (2020). Physical activity, health-related quality of life, and stress among the Chinese adult population during the COVID-19 pandemic. International Journal of Environmental Research and Public Health, 17, 6494. https://doi.org/10.3390/ijerph17186494

Ransdell, L. B., \& Wells, C. L. (1998) Physical activity in urban White, African-American, and Mexican-American women. Medicine \& Science in Sports \& Exercise, 30, 1608-1615. https://doi.org/10.1097/00005768-199811000-00009

Sahu, P. (2020) Closure of Universities Due to Coronavirus Disease 2019 (COVID-19): Impact on education and mental health of students and academic staff. Cureus, 12, e7541. https://doi.org/10.7759/cureus.7541

Shaw, B. A., \& Spokane, L. S. (2008) Examining the association between education level and physical activity changes during early old age. Journal of Aging and Health, 20, 767787. https://doi.org/10.1177/0898264308321081

Theodorakis, Y. (1994) Planned behavior, attitude strength, self-identity, and the prediction of exercise behavior. Sport Psychologist, 8, 149-165. https://doi.org/10.1123/tsp.8.2. 149

Theodorakis, Y., Doganis, G., Bagiatis, K., \& Goudas, M. (1991) Preliminary study of the ability of reasoned action model in predicting exercise behavior of young children. Percept Mot Skills, 72, 51-58. https://doi.org/10.2466/pms.1991.72. 1.51

WHO (2020) Report of the WHO-China joint mission on Coronavirus disease 2019 (COVID-19). Available at: https://www.who.int/docs/default-source/coronaviruse/ who-china-joint-mission-on-covid-19-final-report.pdf

Wilson, T. D., Kraft, D., \& Dunn, D. S. (1989) The disruptive effects of explaining attitudes: the moderating effect of knowledge about the attitude object. Journal of Experimental Social Psychology, 25, 379-400. https://doi.org/10.1016/0022-1031(89)90029-2

Zhai, Y., \& Du, X. (2020) Addressing collegiate mental health amid COVID-19 pandemic. Psychiatry Research, 288, 113003. https://doi.org/10.1016/j.psychres.2020.113003

Zhang, Y., \& Ma, Z. F. (2020) Impact of the COVID-19 pandemic on mental health and quality of life among local residents in Liaoning Province, China: A cross-sectional study. International Journal of Environmental Research and Public Health, 17, 2381. https://doi.org/10.3390/ ijerph17072381 